environment for experimentation with the indicators and reporting on their use against existing health programs (stage four). Professionals involved with the grant projects are being asked to reflect on the process of using the indicators, report on their strengths and weaknesses, and identify any gaps. Their reports will illustrate how the indicators were used; for example: who used them, how often, in what context, and why. We are also interested in finding out how the use of the indicators further influences health promotion practice (stage five).

Moreover, the planned evaluation of the grant scheme will allow us to develop a greater understanding of the dynamics of dissemination and the barriers to it. ${ }^{3}$

Current dissemination research suggests a number of strategies for improving the relationship between research and practice. Nutbeam proposes several approaches, including education and training for practitioners, and a more structured approach to rewarding research development and dissemination efforts. ${ }^{4}$ Oldenburg's analysis of successful dissemination includes strategies that actively involve key stakeholders, provides funding, and ongoing support. ${ }^{5}$ We will be evaluating this grants scheme in terms of how well it has met this challenge of improving the relationship between research and practice.

A range of indicators is being developed to measure capacity, and many practitioners are experimenting with their use without the financial incentive of grants. However, the strength of the grants program is that it intends to establish a dialogue between practitioners and researchers. Green describes the participation of practitioners as a 'rule of thumb' for dissemination: 'the rule of thumb governing the readiness of practitioners to adopt or apply the results of research and development appears to be the degree to which they have been consulted and involved in the formulation of the study'.

The NSW Department of Health has collaborated closely with the Department of Public Health and Community Medicine at the University of Sydney in the development of this set of capacity building indicators. It has also consulted with the key practitioners who are implementing capacity building strategies for health promotion. By doing so it has harnessed some of the growing interest in capacity building research and practice, promoting further this important part of public health practice.

\section{REFERENCES}

1. Hawe P, King L, Noort M, Jordens C, Lloyd B. Indicators to help with capacity building in health promotion. NSW Department of Health and the Australian Centre for Health Promotion, Department of Public Health and Community Medicine, University of Sydney, 2000.

2. King L, Hawe $\mathrm{P}$ and Wise M. From Research into Practice in Health Promotion: A Review of the Literature on Dissemination. Sydney: Australian Centre for Health Promotion, University of Sydney, 1996.

3. MacLean D. Positioning Dissemination in Public Health Policy. Can J Public Health 1996; 87: 6 s18-23

4. Nutbeam D. Improving the Fit between Research and Practice in Health Promotion: Overcoming Structural Barriers. Can J Public Health 1996; 87: 6 s18-23

5. Oldenburg et al. The Dissemination Effort in Australia: Strengthening the links between health promotion research and practice. Canberra: Commonwealth Department of Health and Family Services, 1997.

6. Green L. Three ways research influences policy and practice: the public's right to know and the scientist's responsibility to educate. Health Educ Q 1987; 18: 44-9. Wt

\title{
THE NATIONAL PUBLIC HEALTH PARTNERSHIP
}

\section{National Public Health Partnership Secretariat National Public Health Partnership}

The National Public Health Partnership (NPHP), established in late 1996 by the Australian Health Ministers' Conference, enables closer collaboration and coordination between State, Territory and Commonwealth governments across a range of public health functions and infrastructure areas. This article introduces the structure and function of the NPHP (Figure 3).

The main objectives of the NPHP are to:

- improve the health status of all Australians, in particular population groups most at risk;
- improve collaboration in the national public health effort;

- develop better coordination and increased sustainability of public health strategies;

- strengthen public health infrastructure and capacity nationally;

- establish two-way exchanges with key professional, community, consumer, educational, and industry interests in the development of national public health priorities and strategies;

- facilitate the contribution of public health services, such as local government, public health research and education programs, and other relevant agencies; 
- enhance the capacity of States and Territories to respond to local priorities.

\section{NATIONAL PUBLIC HEALTH PARTNERSHIP GROUP}

The National Public Health Partnership Group operates as a sub-committee of the Australian Health Ministers' Advisory Council (AHMAC). The Partnership Group comprises:

- the Chief Health Officers or Directors of Public Health in all States or Territories, including the First Assistant Secretary of the Public Health Division, Commonwealth Department of Health and Aged Care;

- executive members on the National Health and Medical Research Council and the Australian Institute of Health and Welfare;

- the Director of Public Health of the New Zealand Department of Health, as observer.

The role of the Partnership Group is to oversee the Partnership work program and to report to the AHMAC on progress in key areas of work, including consultation with relevant stakeholders. It makes recommendations to Health Ministers via AHMAC on national priorities for public health, the Partnership work program and other policy issues and responds to matters referred to it by the Australian Health Ministers' Conference and the AHMAC.

\section{THE PARTNERSHIP ADVISORY GROUP}

The Partnership Advisory Group is made up of representatives from key national non-government organisations. The Advisory Group ensures that the National Public Health Partnership is informed of service provider and consumer perspectives on its work program. The organisations represented on the Advisory Group include:

- Australian Health Promotion Association

- Australian Institute of Environmental Health

- Australian Nursing Federation

- Consumers' Health Forum

- National Aboriginal Community Controlled Health Organisation

- Public Health Association of Australia

- Public Health Education and Research Program (PHERP) Directors

- Faculty of Public Health Medicine, Royal Australasian College of Physicians

- The Royal Australian College of General Practitioners.

\section{THE NPHP SECRETARIAT}

The NPHP Secretariat provides direct support services to the NPHPG. Situated in Melbourne, it coordinates research that supports policy developed by the NPHP; and provides additional support services including the Australian Institute of Health and Welfare's role as secretariat for the National Public Health Information Working Group.

\section{THE NPHP WORK PROGRAM}

The NPHP work program concurrently focuses on building capacity and infrastructure supporting public health, and on specific public health areas. While priority work areas are set, issues within these areas continue to emerge and evolve.

Examples of activity in the six priority work-areas include:

\section{Legislation Reform}

The review and harmonisation of public health legislation across the nation, such as to address passive smoking and immunisation.

\section{Workforce Development}

The implementation of national public health workforce development initiatives, with current priorities in environmental health, health promotion and leadership.

\section{Research and Development}

The strengthening of national public health research and development capacity, in conjunction with the National Health and Medical Research Council, including contributions to the Health and Medical Research Strategic Review (Wills Review) on the future directions of health and medical research.

\section{National Strategies Coordination}

The development of better coordination and increased sustainability in national public health strategies, especially in the areas of chronic disease and communicable disease prevention.

\section{Planning and Practice Improvement}

The development of standards for the delivery of core public health functions and appropriate planning and resource allocation methods.

\section{Information}

The implementation of the National Public Health Information Development Plan.

Examples of NPHP involvement in other key national issues include:

- support for the development of the National Environmental Health Strategy, utilising technical advice from the EnHealth Council (formerly the National Environmental Health Forum).

- support for developments in food safety and nutrition, focusing on the consistent implementation of the National Food Standards across jurisdictions.

- collaboration on the national strategic response to hepatitis $\mathrm{C}$, including assistance with coordination. 


\section{FIGURE 3}

\section{STRUCTURE OF THE NATIONAL PUBLIC HEALTH PARTNERSHIP}

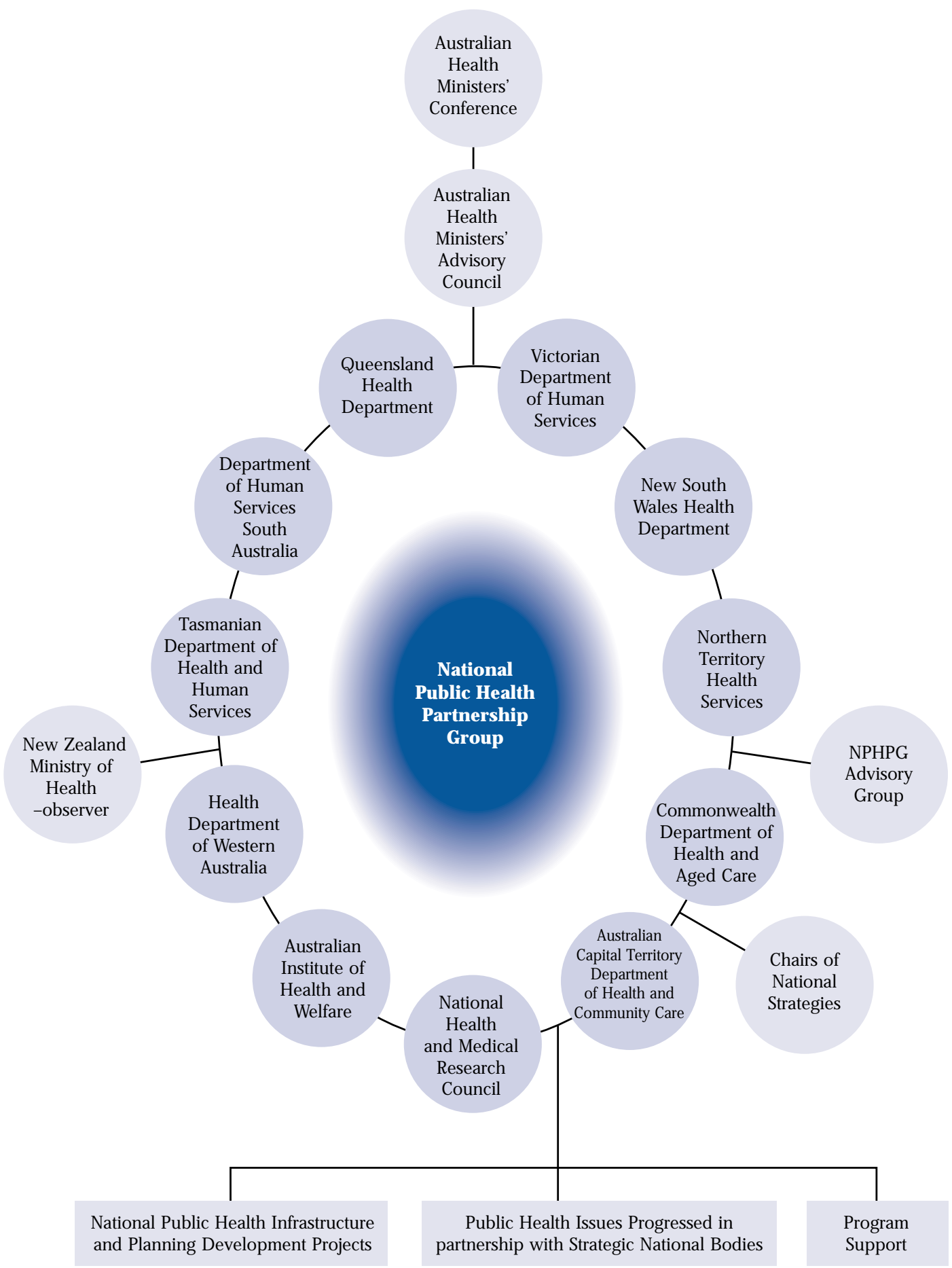


- collaboration with the AHMAC National Mental Health Working Group to develop an action plan for promoting mental health and preventing illness.

- creation of the Joint Advisory Group on General Practice and Population Health.

As new public health issues emerge, the Partnership Group, through its work program, can draw on specialist knowledge of national groups, other organisations and individuals, including the National Health and Medical Research Council, and the Australian Institute of Health and Welfare.
While the NPHP is an alliance of governments, it also places great emphasis on developing and participating in other partnerships to foster collaboration in national public health. Other providers of public health, such as local government, public health research and education programs, and relevant agencies from States/Territories and the Commonwealth are also involved in work program activities. 政

To find out more information about the NPHP contact Darryl Kosch at the secretariat by telephone: (03) 9637 5512; facsimile: (03) 9637 5510; email: nphp@dhs.vic.gov.au; or by visiting the NPHP Web site at www.dhs.vic.gov.au/nphp.

\section{Progress through Partnerships: Highlights of Public Health Activities in Australia}

The National Public Health Partnership has released the first of its annual reports Progress through Partnerships: Highlights of Public Health Activities in Australia. The report provides an understanding of the range of public health activities undertaken in Australia during 1998-99. It includes a summary of NPHP activities during the year, information on each of the national public health strategies, and contributions from all jurisdictions on public health achievements for the previous twelve months.

The annual report will be a useful resource for all those working in public health nationally, as well as providing those outside the sector with an understanding of the nature of Australia's public health effort. The report is available on the NPHP Web site or by telephoning the NPHP secretariat.

\section{NSW HEALTH HEPATITIS C PUBLIC AWARENESS CAMPAIGN}

\section{Brent Mackie \\ AIDS/Infectious Diseases Unit \\ NSW Department of Health}

The NSW Health Hepatitis C Public Awareness Campaign is a new campaign targeting Hepatitis $\mathrm{C}(\mathrm{HCV})$ conducted by the NSW Department of Health in partnership with a range of government and non-government organisations. This article describes the campaign, including its background and development.

The campaign, which will run during March and April 2000 , will target the complex issues of increasing awareness of $\mathrm{HCV}$, and will include a statewide television advertising campaign aimed at reducing misinformation and creating an environment supportive of $\mathrm{HCV}$ prevention programs using social marketing techniques. It is hoped that the campaign will also encourage people concerned about HCV to seek advice and, where appropriate, testing from their local General Practitioner.

\section{BACKGROUND}

It is estimated that there are approximately 200,000 people in Australia infected with HCV. The rate of new infections is estimated to be 11,000 people annually, ${ }^{1}$ with NSW accounting for over 40 per cent of all $\mathrm{HCV}$ cases, in terms of both prevalence and incidence. ${ }^{2}$

Prevention of $\mathrm{HCV}$ infection to date has concentrated on the development of health education programs targeting high-risk populations, and measures such as needle and syringe programs. No previous $\mathrm{HCV}$ information and education campaign in the mass media has targeted the general community in Australia. There are, however, a number of reasons why a mass media campaign would be an effective prevention and education measure. These 